\title{
Treatment of cancer cachexia in mice by combination of dsRNA-dependent protein kinase inhibitor and medroxyprogesterone acetate
}

\author{
SI-ZENG CHEN and YONG-LIAN ZHANG \\ Department of Gastrointestinal Surgery, The First Affiliated Hospital, Fujian Medical University, Fujian 350005, P.R. China
}

Received August 11, 2011; Accepted October 10, 2011

DOI: $10.3892 /$ or.2011.1540

\begin{abstract}
Inhibitor of dsRNA-dependent protein kinase (PKRI) and medroxyprogesterone acetate (MPA) improve cancer cachexia via different mechanisms. We aimed to compare these two drugs, alone or in combination, in cancer cachexia in mice. Forty male BABL/c mice aged 6-8 weeks were randomly divided into PKRI, MPA, PKRI+MPA, placebo, and healthy control groups. The first 4 groups were injected with colon-26 adenocarcinoma and fed for 12 days and then treated with PKRI and MPA alone or in combination for 7 days. Body weight, tumor volume, wet weight of gastrocnemius muscle, serum levels of nutritional markers and cytokines were measured. The tumor growth (volume and weight) of mice treated with PKRI, MPA alone or PKRI+MPA was slower than that of placebo group. Wet weight of gastrocnemius muscle was significantly higher in PKRI and PKRI+MPA-treated than in placebo animals $(\mathrm{P}<0.01)$. All tumor-bearing mice had a significantly lower level of blood glucose, higher level of serum triglyceride and lower level of serum albumin compared with healthy control $(\mathrm{P}<0.001)$. However, PKRI, MPA and PKRI+MPA groups had a significant higher level of blood glucose and lower level of serum triglyceride compared with placebo group $(\mathrm{P}<0.001)$. All tumor bearing mice had a significant higher level of serum TNF- $\alpha$, IL-1 and IL-6 compared with healthy control $(\mathrm{P}<0.001)$. Serum level of TNF- $\alpha$ and IL- 6 was significantly lower in PKRI and PKRI+MPA-treated than in placebo animals $(\mathrm{P}<0.01)$. PKRI alone and combination therapy with PKRI and MPA reduce tumor growth and may alleviate cachexia.
\end{abstract}

Correspondence to: Dr Si-Zeng Chen, Department of Gastrointestinal Surgery, The First Affiliated Hospital, Fujian Medical University, No. 20 Chating Zhong Road, Fuzhou, Fujian 350005, P.R. China

E-mail: chensz04871@hotmail.com

Key words: cancer cachexia, inhibitor of dsRNA-dependent protein kinase, medroxyprogesterone acetate, muscle wasting, anorexia

\section{Introduction}

Cancer cachexia (CC) is a complication of end stage cancer, characterized by progressive loss of body weight and metabolic disorders. It leads to compromised quality of life and shortened survival time. The pathogenesis of cancer cachexia is multiple, and the potential mechanisms have been extensively studied. But there is still little known about clinical treatment of this condition (1-3). Many trials have been performed in the search for a treatment for cachexia, but most therapies have not fulfilled expectations (4-6). Therefore, continuing to probe the pathogenesis and therapies of cancer cachexia holds clinical significance.

One metabolic abnormality in cancer cachexia is a loss of skeletal muscle protein, due to a depression in protein synthesis (7) combined with an increase in protein degradation (8), both events initiated by inflammatory mediators and by cachectic factors released from tumor tissue (9). Recent research (10) has shown activation of dsRNA-dependent protein kinase (PKR), a serine/threonine kinase, responsible for the linking two cachectic signaling molecules, proteolysis-inducing factor (PIF) and angiotensin II (Ang II), to decreased synthesis and increased degradation of skeletal muscle protein.

In response to catabolic stimuli such as PIF and Ang II, PKR binds its activator, dsRNA (11) and is activated through autophosphorylation. Active PKR phosphorylates $\alpha$-subunit of the translation factor, eukaryotic initiation factor 2 (eIF2- $\alpha$ ) and the phosphorylated eIF2- $\alpha$ acts as a competitive inhibitor to prevent translation initiation and thus inhibit synthesis of muscle protein (12). PKR also activates the transcription factor, nuclear factor $-\kappa \mathrm{B}(\mathrm{NF}-\kappa \mathrm{B})$, through phosphorylation and removal of the inhibitor of $\kappa \mathrm{B}$ (13) thus, increasing protein degradation by inducing the ubiquitin-proteasome pathway.

The inhibitor of dsRNA-dependent protein kinase (PKRI) is an imidazolo-oxindole compound that inhibits PKR autophosphorylation and activation (14). PKRI has been shown to attenuate muscle atrophy in the MAC16 murine cachexia model through increasing protein synthesis and decreasing protein degradation (15). These data suggest that inhibitors of PKR activation may be useful in the treatment of cancer cachexia.

A second metabolic abnormality in cancer cachexia is a loss of fat stores that is often accompanied by loss of appe- 
tite. Medroxyprogesterone acetate (MPA, chemical name $17-\alpha$-acetoxy- $6 \alpha$-methylprogesterone) (16) currently is the only approved drug in Europe for the clinical treatment of cancer cachexia syndrome. In placebo-controlled trials, MPA led to increased appetite and weight gain and improved quality-oflife, although the weight gain was due to increased body fat since muscle protein was not significantly affected (17).

Reports from previous preclinical and clinical studies suggest that suppression of secretion of some cytokines (such as TNF- $\alpha$ and IL-6) may, at least in part, cause the anticachectic effect of MPA (18-20). There is also evidence that MPA may stimulate appetite through a CNS action involving neuropeptide Y (21).

Because PKRI mainly improves protein metabolism and MPA mainly improves appetite and increases body fat, there may be an advantage to combination therapy with these two drugs. The present study was performed to evaluate the effect of PKRI and MPA, alone and in combination, on cancer cachexia mice and to investigate potential mechanisms for their effects.

\section{Materials amd methods}

Materials. PKRI (Merck KGaA) was dissolved in 10\% DMSO diluted with PBS. MPA (LKT Labs, St. Paul, MN, USA) was dissolved in $2 \%$ Tween-80 diluted with regular saline solution. The colon-26 (C-26) adenocarcinoma specimen was purchased from Institute of Material Medical, Chinese Academy of Medical Sciences (Beijing). All the kits for enzyme-linked immunosorbent assay (ELISA) were purchased from R\&D Systems, Inc. (USA).

Animals. BALB/c male mice (6-8-week old, 20-24 g body weight) were purchased from the Animal Center of the Chinese Academy of Sciences (Shanghai, China; SPF certificate numbers: SCXK (Hu)2007-0005). Specific pathogen-free housing and care was provided by the Animal Center of Fujian Medical University, which provided free access to standard laboratory chow and tap water in a temperature-controlled room $\left(22 \pm 1^{\circ} \mathrm{C}\right)$ on a 12 -h light-dark cycle. The experimental protocol was approved by the Animal Use Committee at our institution.

Forty healthy mice were randomly divided into 5 groups: (A) PKRI group, (B) MPA group, (C) PKRI+MPA group, (D) placebo group and (E) healthy control group $(n=8$ in each group). Mice in the first four groups were injected s.c. in the anterior subaxilla with a homogenate of $50 \mathrm{mg}\left(2-3 \mathrm{~mm}^{3}\right)$ of minced solid murine $\mathrm{C}-26$ adenocarcinoma in $0.1 \mathrm{ml} 0.9 \%$ $\mathrm{NaCl}$ (Day 1), as previously described (22). Day 12 was chosen for establishment of cachexia since by Day 12, the non-tumor weights of the tumor-bearing mice are significantly different from those of healthy mice, together with apparent cachexic signs and symptoms (poor physical activity, asthenia, piloerection, shedding, and non-glossy fur) $(15,23)$.

On Day 12, different interventions were implemented in all groups. Mice in PKRI group were administered with $100 \mu \mathrm{l}$ PKRI (5 mg/kg) s.c. and $1.0 \mathrm{ml} 5 \%$ Tween-80 intragastrically while mice in MPA group was administered with $100 \mu 110 \%$ DMSO s.c. and $1.0 \mathrm{ml}$ MPA $(120 \mathrm{mg} / \mathrm{kg})$, intragastrically. In addition, mice in PKRI+MPA group were administered with
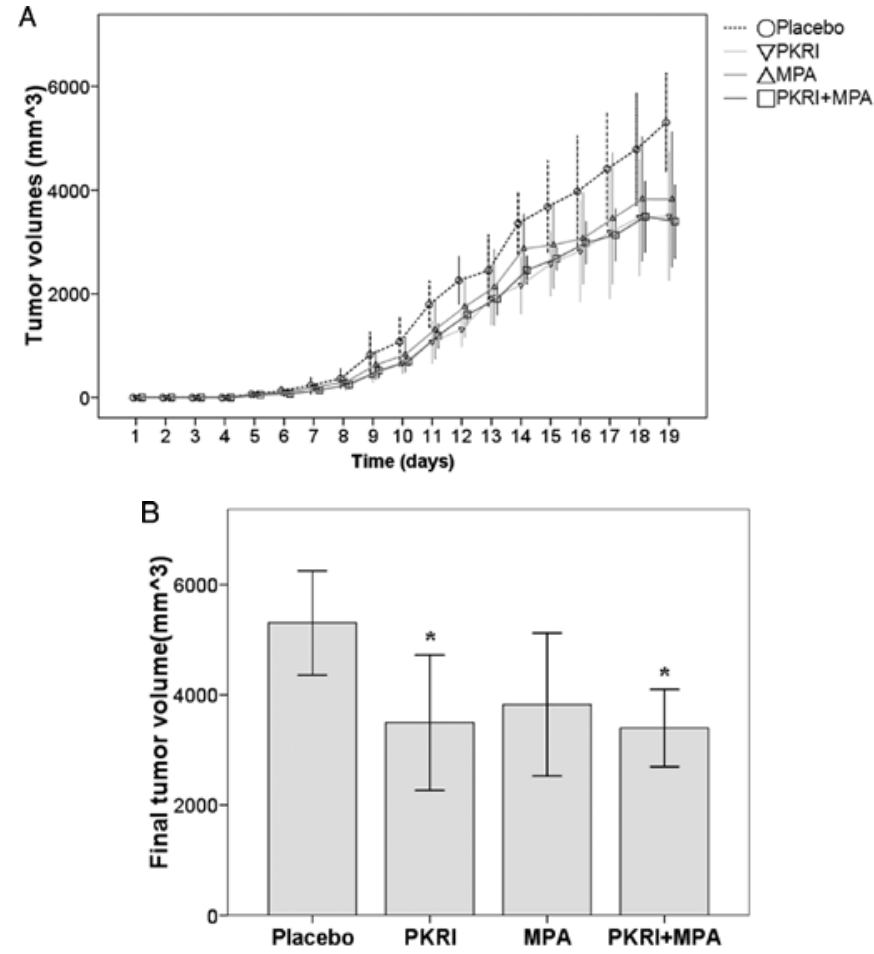

Figure 1. Tumor volume change in tumor-bearing mice. (A) Time course of tumor volume change in healthy and tumor-bearing mice. Tumors can be felt from Day 5 on and their growth accelerates from Day 8 on till Day 19. Tumor volume of the PKRI, MPA, and PKRI+MPA groups was lower than that of placebo from Day 9 on $(\mathrm{P}<0.05)$. (B) Effect of different treatments on final tumor volumes. ${ }^{\mathrm{P}}<0.05$ comparing to group placebo; all, after Bonferroni adjustment, mean $\pm \mathrm{SD}, \mathrm{n}=8$ in each group. PKRI, inhibitor of dsRNAdependent protein kinase; MPA, medroxyprogesterone.

$100 \mu \mathrm{l}$ PKRI $(5 \mathrm{mg} / \mathrm{kg})$ s.c. and $1.0 \mathrm{ml} \mathrm{MPA}(120 \mathrm{mg} / \mathrm{kg})$ intragastrically while mice in placebo group and control group received $100 \mu 1$ 10\% DMSO s.c. and $1.0 \mathrm{ml} 5 \%$ Tween-80, intragastrically. All the mice were administered once a day for seven days.

Physical activity, fur condition, body weight, food intake and tumor inoculation site for all mice were monitored daily from Day 1. Tumor volume $\left(\mathrm{V}, \mathrm{cm}^{3}\right)$ was estimated from Day 5 onward using the formula $\mathrm{V}=a b^{2} / 2$, where ' $\mathrm{a}$ ' is length and ' $b$ ' is width. When the treatments were finished (Day 19), blood samples from anesthetized mice were collected from orbital veins by enucleation of the eyeball and subjected to centrifugation at $4000 \mathrm{rpm}$ for $10 \mathrm{~min}$. The resulting serum was collected and stored at $-20^{\circ} \mathrm{C}$ for further study. Finally all mice were sacrificed by cervical dislocation. The tumors in the tumor-bearing mice and the left rear gastrocnemius muscles in all laboratory mice were then quickly dissected out and precisely weighed.

Biochemistry. Blood glucose (Glu), serum triglyceride (Tg), serum albumin (Alb) and total protein (TP), used as biochemical indicators of nutritional status, were measured by routine analysis. (Olympus AU2700 Biochemistry Analyzer, Japan).

Enzyme-linked immunosorbent assay (ELISA). Serum cytokines such as TNF- $\alpha$, IL-1 and IL- 6 are closely linked with cachexia. The serum levels of these three cytokines were measured by ELISA as instructed by the manufacturers. 

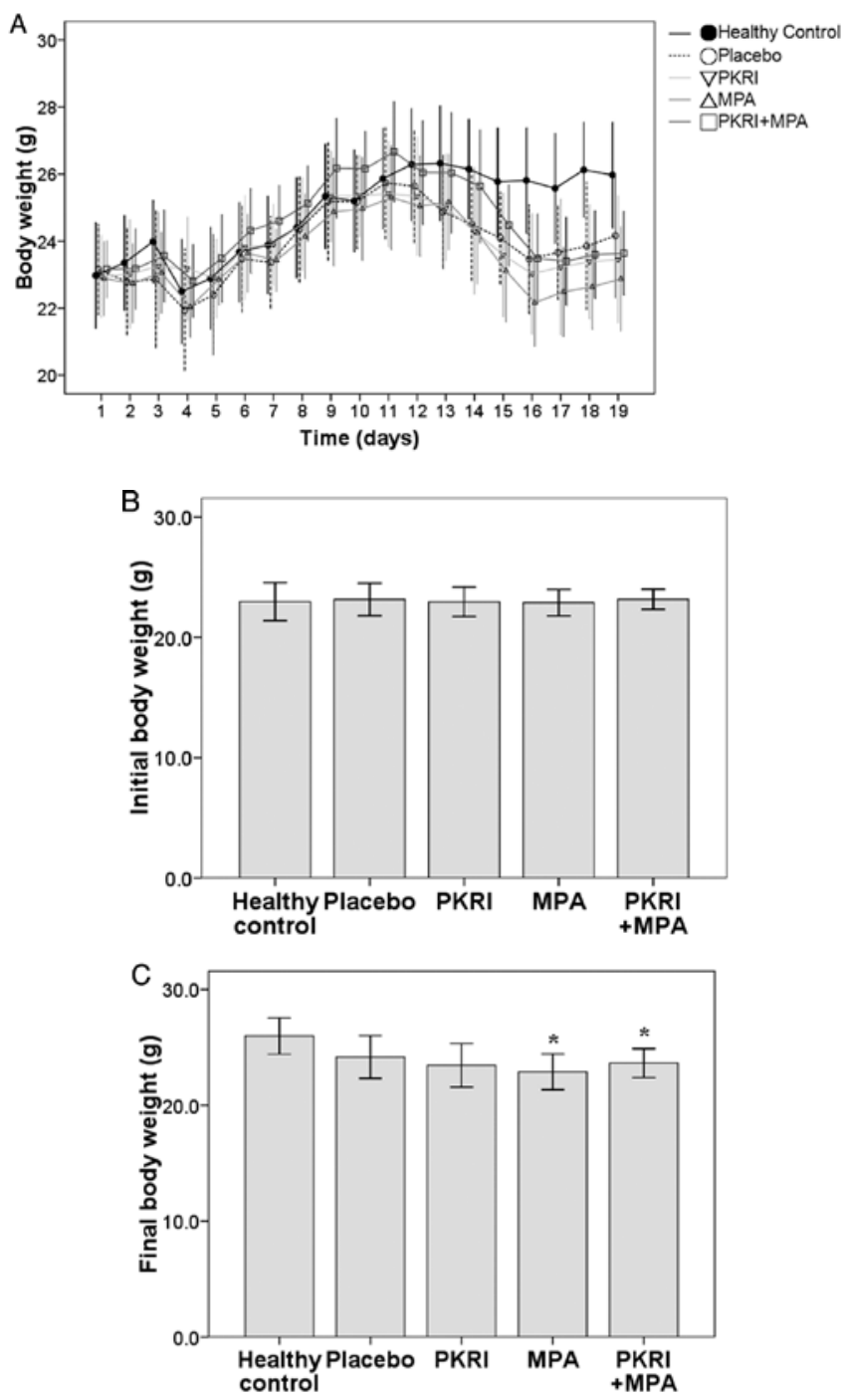

Figure 2. Body weight change and tumor weight change in tumor-bearing mice. (A) Time course of body weight change in healthy and tumor-bearing mice. (B) Effect of different treatments on initial body weight and (C) effect of different treatments on final body weight and tumor weights of the tumorbearing mice. " $\mathrm{P}<0.05$ compared to placebo group; all after Bonferroni adjustment, mean $\pm \mathrm{SD}, \mathrm{n}=8$ in each group. PKRI, inhibitor of dsRNAdependent protein kinase; MPA, medroxyprogesterone.

Statistical analysis. Means and standard deviations were calculated for each group. Tumor volume and body weight measured over study period were analyzed at the end of Day 19. Comparisons were performed with ANOVA with post-hoc comparison adjusted by the Bonferroni method. Data were analyzed with SAS 9.0 (SAS Institute Inc., Cary, $\mathrm{NC}$ ), and a P-value $<0.05$ was considered statistically significant.

\section{Results}

Tumor volume. The tumors of tumor-bearing mice could be touched from Day 5 on. The growth of the tumor accelerated from Day 8 on and the increase in tumor volume of mice treated with PKRI, MPA alone or PKRI+MPA was slower than that of mice treated with placebo (Fig. 1A). On Day 19, mice treated with PKRI and PKRI+MPA had a significantly smaller
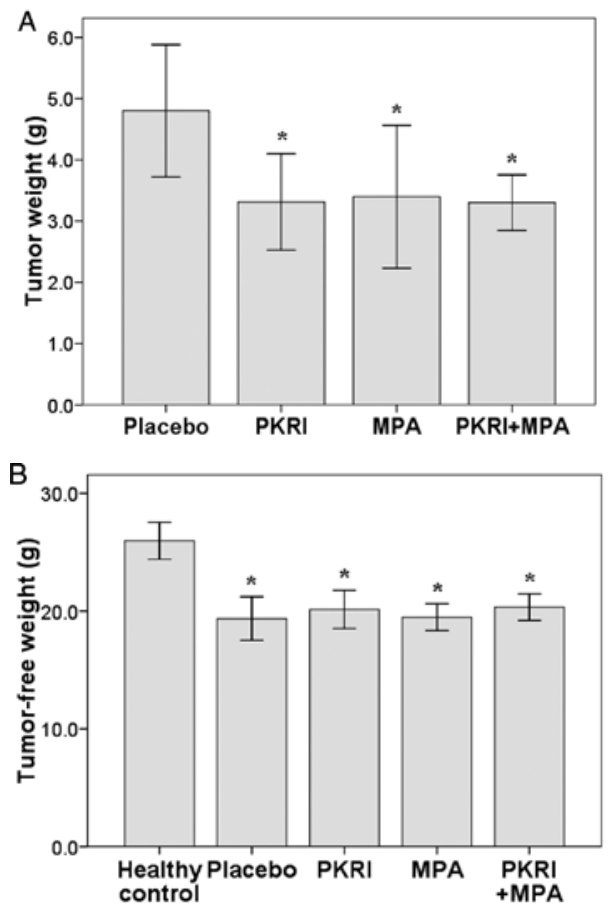

Figure 3. Tumor weight. (A) Effect of different treatments on tumor weights of the tumor-bearing mice. (B) Effect of different treatments on tumor-free body weight. ${ }^{*} \mathrm{P}<0.05$ comparing to group placebo; all, after Bonferroni adjustment, mean $\pm \mathrm{SD}, \mathrm{n}=8$ in each group. PKRI, inhibitor of dsRNAdependent protein kinase; MPA, medroxyprogesterone.

tumor volume (final tumor volume) than mice treated with placebo (Fig. 1B, $\mathrm{P}=0.013$ and $\mathrm{P}=0.008$, respectively).

Body weight. The body weight of mice in the five groups had no significant differences between them at the beginning and for several days. The body weight of tumor-bearing mice began to decline on Day 11, and dropped to the lowest levels on Day 16 , and then had a slight increase because of the tumor growth (Fig. 2A). There was no difference in body weight between the groups at the beginning of the experiment (Fig. 2B). At the end of experiment, there was a slightly but significantly lower body weight in MPA and PKRI+MPA groups comparing with the healthy control group (Fig. 2C).

Tumor weight and tumor-free body weight. On Day 19, the tumor weights of groups PKRI, MPA and PKRI+MPA were significantly different from that of the placebo group (Fig. 3A), $\mathrm{P}=0.039, \mathrm{P}=0.06,<0.01$, respectively). A significantly lower tumor-free body weight was found in all treatment groups compared to that of the healthy control group (Fig. 3B).

Muscle weight. Skeletal muscle (gastrocnemius wet weight) weight was significantly lower in all tumor-bearing groups than in the healthy control group $(\mathrm{P}<0.01)$. Skeletal muscle weight was significantly higher in PKRI and PKRI+MPAtreated than in placebo animals $(\mathrm{P}<0.01)$, but showed no significant increase over body weight of placebo-treated animals in animals treated with MPA alone (Fig. 4). In fact, skeletal muscle weight was significantly higher also in PKRI and PKRI+MPA-treated than in animals treated with MPA alone $(\mathrm{P}<0.01)$. 


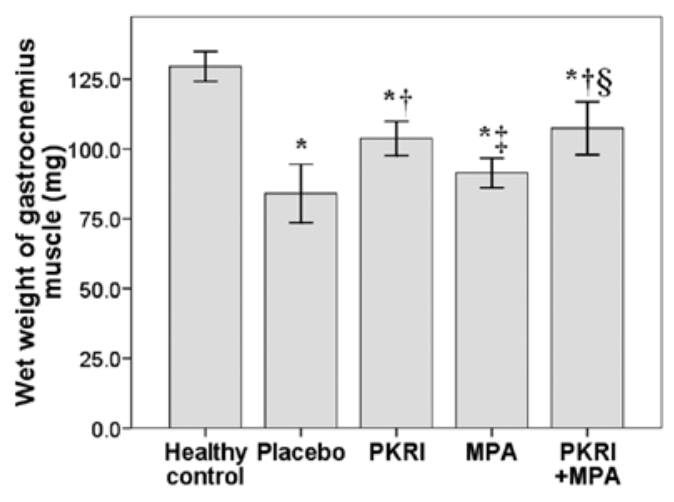

Figure 4. Wet weight of the left rear gastrocnemius muscle. Effect of different treatments on wet weight of gastrocnemius muscle. $\mathrm{P}<0.05$ indicates significant difference, compared to healthy control $\left({ }^{*}\right)$, placebo $\left({ }^{\dagger}\right)$, PKRI ( $\left.{ }^{\ddagger}\right)$ and MPA $\left({ }^{\S}\right)$, respectively after Bonferroni adjustment, mean $\pm \mathrm{SD}, \mathrm{n}=8$ in each group.

Metabolic indicators. All tumor-bearing mice had a significantly lower level of blood Glu (Fig. 5A) and a significant higher level of serum Tg (Fig. 5B) compared with healthy control animals (all, $\mathrm{P}<0.001$ ). Furthermore, the PKRI, MPA and PKRI+MPA groups had a significantly higher level of blood glucose (Glu) and a significantly lower level of serum triglyceride (TG) compared with placebo group (all, $\mathrm{P}<0.001$ ). Serum total protein (STP) was significantly lower in the placebo group than in healthy controls but it returned to normal level in all treatment groups (Fig. 5C). Group PKRI, MPA, PKRI+MPA and placebo groups had a significantly lower level of serum albumin (Alb) compared with healthy control (all, $\mathrm{P}<0.001$ ) (Fig. 5D).

Serum cytokines. For the serum level of TNF- $\alpha$, PKRI, MPA, PKRI+MPA and placebo groups were significantly higher than healthy control (Fig. 6A). Serum level of TNF- $\alpha$ was significantly lower in PKRI and PKRI+MPA-treated than in placebo animals $(\mathrm{P}<0.01)$, but showed no significant decrease in animals treated with MPA alone (Fig. 6A). In fact, the serum level of TNF- $\alpha$ was significantly lower also in PKRI and PKRI+MPA-treated than in animals treated with MPA alone $(\mathrm{P}<0.01)$. All tumor bearing mice had a significantly higher level of serum IL-1 compared with healthy controls (all, $\mathrm{P}<0.001$ ) (Fig. 6B). All tumor bearing mice had a significantly higher level of serum IL-6 compared with healthy control (all, $\mathrm{P}<0.001$ ) (Fig. 6C). The serum level of IL-6 was significantly lower in PKRI and PKRI+MPA-treated than in placebo animals $(\mathrm{P}<0.01)$, but showed no significant decrease in animals treated with MPA alone (Fig. 6C). In fact, the serum level of IL-6 was significantly lower also in PKRI and PKRI+MPA-treated than in animals treated with MPA alone $(\mathrm{P}<0.01)$.

\section{Discussion}

In this study, we compared the effects of treatment with PKRI, an inhibitor of dsRNA-inducible protein kinase, and MPA, a progesterone analog, alone or in combination, in a mouse model of cancer cachexia. Cancer cachexia is a complex condition including reduced food intake, muscle wasting, anemia, and changes in immune function. The muscle wasting seen in cachexia is due to reduced protein synthesis due to increased
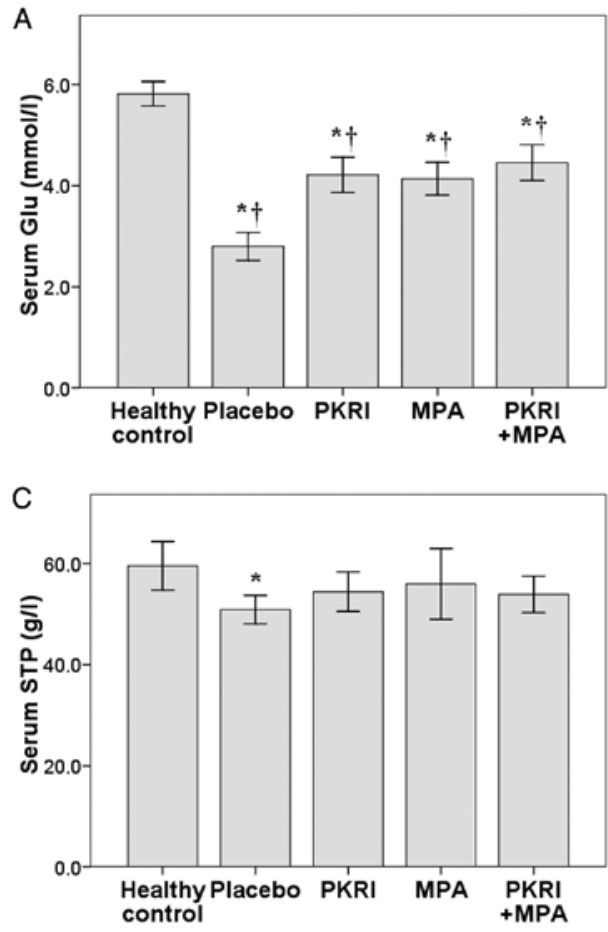
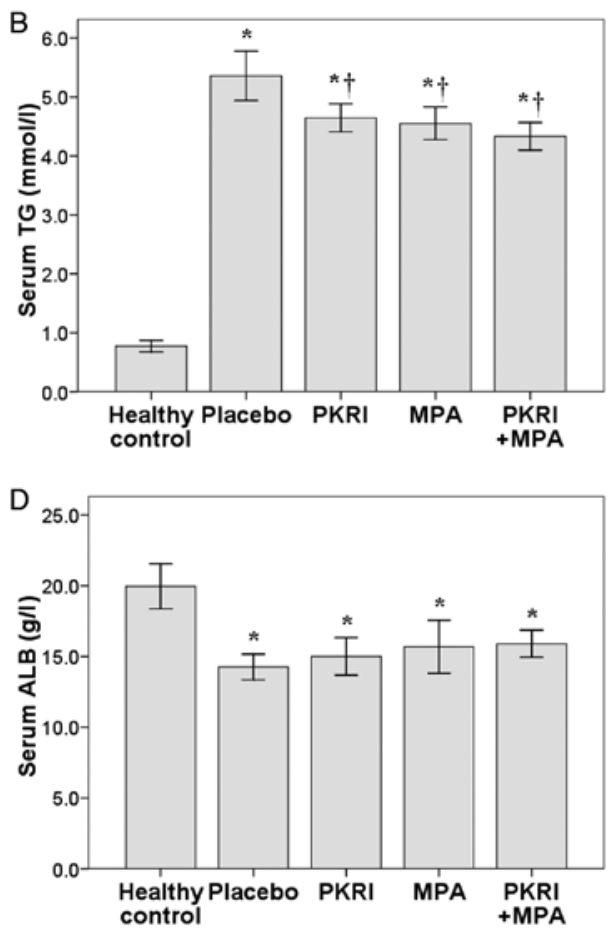

Figure 5. Effect of different treatments on serum nutritional markers. (A) Blood glucose (Glu); (B) serum triglyceride (Tg); (C) serum total protein (STP); (D) serum albumin (Alb). $\mathrm{P}<0.05$ indicates significant difference compared to healthy control $\left(^{*}\right)$ and placebo $\left({ }^{\dagger}\right)$, after Bonferroni adjustment, mean $\pm \mathrm{SD}$, $\mathrm{n}=8$ in each group. 

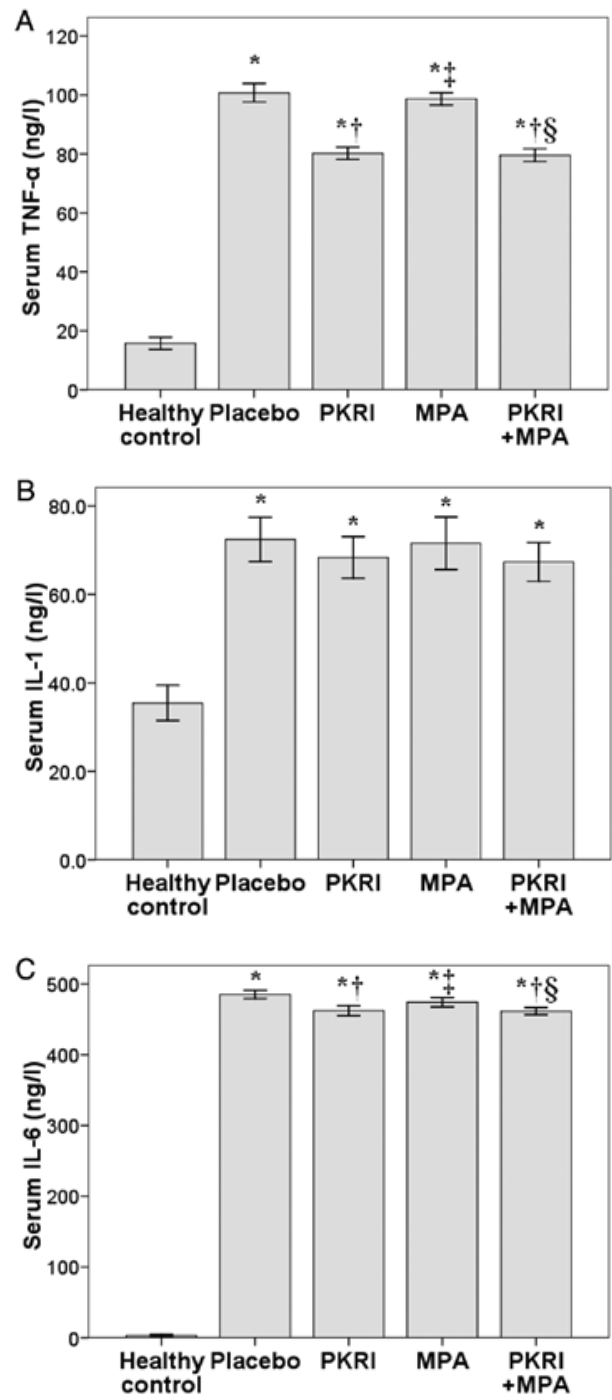

Figure 6. Effect of different treatments on serum cytokines. (A) TNF- $\alpha$; (B) IL-1; (C) IL-6. P<0.05 indicates significant difference, compared to healthy control $\left({ }^{*}\right)$, placebo $(\dagger)$, PKRI $\left({ }^{\ddagger}\right)$ and MPA $\left({ }^{(}\right)$respectively after Bonferroni adjustment, mean $\pm S D, n=8$ in each group.

phosphorylation by dsRNA-dependent protein kinase of the initiation factor eFI 2 and subsequent decreased binding of methionyl tRNA to the 40S ribosomal subunit, and to increased protein degradation through the ubiquitin-proteosome pathway. Proteolysis-inducing factor (PIF), a glycoprotein secreted by tumors, and substances such as glucocorticoids, angiotensin II, and TNF $\alpha$ can all cause muscle wasting (24). Several new agents, including androgen-receptor modulators and antagonists of inflammatory cytokines that promote muscle breakdown, are currently in clinical development for cancer cachexia treatment $(6,24,25)$.

In our study, tumor growth (both tumor volume and tumor weight) of mice treated with PKRI, MPA, and PKRI+PKA was slower than that of mice treated with placebo. On Day 19, the tumor weight of PKRI, MPA, and PKRI+MPA groups was significantly lower than that of the placebo group. Skeletal muscle weight (gastrocnemius wet weight) was significantly lower in all tumor-bearing groups than in the healthy control group $(\mathrm{P}<0.01)$. However, it was significantly higher in PKRI and PKRI+MPA-treated than in placebo-treated animals $(\mathrm{P}<0.01)$.

Our finding was supported by previous reports. The administration of MPA, in placebo-controlled trials, has been reported to improve body weight, anorexia, and quality of life, but to improve body weight only by increasing fat and not by increasing muscle protein (17). However, it has been suggested that the combination of MPA and other anti-cachectic treatments might have therapeutic value (17). PKRI has been shown to decrease both tumor growth and skeletal muscle atrophy in a mouse model of MAC16 cancer cachexia (26). In vitro in MAC16 tumor cells, PKRI inhibited cell proliferation at a concentration of $200 \mathrm{nM}$, a concentration that also caused maximal inhibition of PKR and eIF2 phosphorylation (26). In another in vitro study, PKRI completely blocked both the Ang II and PIF-induced increase in proteasome expression and activity and the accompanying increase in protein degradation, presumably by preventing PIF and Ang II-caused nuclear migration of the transcription factor NF- $\kappa \mathrm{B}(10)$.

All tumor-bearing mice had a significantly higher levels of serum triglyceride compared with healthy controls. Cancer cachexia is characterized by the uncontrolled loss of adipose and muscle mass (27). Compared with non-tumor-bearing animals, the rate of triglyceride production increased almost threefold in animals bearing the MAC13 tumor (28). In our study, the PKRI, MPA, and PKRI+MPA groups had a significantly lower level of triglyceride than the placebo group. The inhibition of lipolysis through genetic ablation of adipose triglyceride lipase or hormone-sensitive lipase significantly ameliorates certain features of cancer cachexia (27).

All tumor-bearing mice had a significantly lower level of blood glucose compared with healthy controls. In our study, the PKRI, MPA, and PKRI+MPA groups had a significantly higher level of blood glucose than the placebo group. The mechanism of decrease in the level of glucose in tumor-bearing mice is unknown. It might result from reducing appetite (reduced food intake). Whether the higher level of blood glucose in PKRI, MPA, and PKRI+MPA groups associated with increase in appetite remained to be studied.

All tumor-bearing mice had significantly higher levels of TNF- $\alpha$, IL-1, and IL-6 compared to healthy controls. Serum levels of TNF- $\alpha$ and IL-6 were significantly lower in PKRI and PKRI+MPA-treated animals than in placebo-treated animals, but showed no significant decrease compared to placebo-treated animals in animals treated with MPA alone. In fact, the serum levels of TNF- $\alpha$ and IL- 6 were significantly lower in PKRI and PKRI-treated animals than in animals treated with MPA alone as well $(\mathrm{P}<0.01)$.

TNF $\alpha$, IL-1 and IL- 6 are all elevated on cancer cachexia and have all been implicated in its causation, but to different degrees $(29,30)$. IL-1 is clearly involved in the induction of anorexia, through its inhibition in the CNS of the orexogenic peptide NPY (9). TNF $\alpha$ is thought to decrease protein synthesis and increase protein degradation through $\mathrm{NF}-\kappa \mathrm{B}$ and the JAK/STAT pathway. Its cachectic and muscle-wasting action is facilitated in the presence of IL-1B or IL-6, but is not always seen when it is administered alone $(24,30)$. Tumors are an important source of IL-6, and its action in causing cancer cachexia has been well documented. Like TNF $\alpha$, its actions are also thought to be on the JAK/STAT pathway (29). 
MPA, in our study, had no significant effect on skeletal muscle mass, which is similar to reports for progestagens in clinical studies (17). However, a recent study of megestrol acetate in tumor-bearing rats reported a reversal of muscle wasting (31). Progestagens are thought to increase appetite at least in part by decreasing the synthesis and release of proinflammatory cytokines $(17,24)$. However, in our study, MPA had no significant effect on serum levels of the three cytokines studied, TNFa, IL-1, and IL-6.

In conclusion, PKRI alone and combination therapy with PKRI and MPA reduce tumor growth and may alleviate cachexia.

\section{Acknowledgements}

This study was supported by a research grant (no. JS06045) from Professor Academic Development Fund of Fujian Medical University.

\section{References}

1. Skipworth RJ, Stewart GD, Dejong CH, Preston T and Fearon KC: Pathophysiology of cancer cachexia: much more than host-tumour interaction? Clin Nutr 26: 667-676, 2007.

2. George J, Cannon T, Lai V, Richey L, Zanation A, Hayes DN, Shores C, Guttridge D and Couch M: Cancer cachexia syndrome in head and neck cancer patients: Part II Pathophysiology. Head Neck 29: 497-507, 2007.

3. Bennani-Baiti $\mathrm{N}$ and Davis MP: Cytokines and cancer anorexia cachexia syndrome. Am J Hosp Palliat Care 25: 407-411, 2008.

4. Topkan E, Yavuz AA and Ozyilkan O: Cancer cachexia: pathophysiologic aspects and treatment options. Asian Pac J Cancer Prev 8: 445-451, 2007.

5. Bachmann J, Friess H and Martignoni ME: Molecular mechanisms and its clinical impact in cancer cachexia. Z Gastroenterol 46: 1384-1392, 2008.

6. Dodson S, Baracos VE, Jatoi A, Evans WJ, Cella D, Dalton JT and Steiner MS: Muscle wasting in cancer cachexia: clinical implications, diagnosis, and emerging treatment strategies. Ann Rev Med 62: 265-279, 2011.

7. Emery PW, Edwards RHT, Rennie MJ, Souhami RL and Halliday D: Protein synthesis in muscle measured in vivo in cachectic patients with cancer. BMJ 289: 584-589, 1984.

8. Lundholm K, Bennegard K, Eden E, Svaninger G, Emery PW and Rennie MJ: Efflux of 3-methylhistadine from the leg in cancer patients who experience weight loss. Cancer Res 42: 4807-4811, 1982.

9. Argiles JM, Busquets S, Toledo M and Lopes-Soriano FJ: The role of cytokines in cancer cachexia. Curr Opin Support Palliat Care 3: 263-268, 2009.

10. Eley HL and Tisdale MJ: Skeletal muscle atrophy, a link between depression of protein synthesis and increase in degradation. J Biol Chem 282: 7087-7097, 2007.

11. Clemens MJ: PKR - a protein kinase regulated by doublestranded RNA. Int J Biochem Cell Biol 29: 945-949, 1997.

12. Panniers R and Henshaw EC: A GDP/GTP exchange factor essential for eukaryotic initiation factor 2 cycling in Ehrlich ascites tumor cells and its regulation by eukaryotic initiation factor 2 phosphorylation. J Biol Chem 258: 7928-7934, 1983.
13. Kumar A, Haque J, Lacoste J, Hiscott J and Williams BRG: Double-stranded RNA-dependent protein kinase activates transcription factor NF- $\kappa$ B by phosphorylating $I \kappa B$. Proc Natl Acad Sci USA 91: 6288-6292, 1984.

14. Jammi NV, Whitby LR and Beal PA: Small molecule inhibitors of the RNA-dependent kinase. Biochem Biophys Res Commun 308: 50-57, 2003.

15. Eley HL, Russell ST and Tisdale MJ: Attenuation of muscle atrophy in a murine model of cachexia by inhibition of the dsRNA-dependent protein kinase. Br J Cancer 96: 1216-1222, 2007.

16. Blei F, Wilson EL, Mignatti P and Rifkin DB: Mechanism of action of angiostatic steroids: suppression of plasminogen activator activity via stimulation of plasminogen activator inhibitor synthesis. J Cell Physiol 155: 568-578, 1993.

17. Madeddu C, Maccio A, Panzone F, Tanca FM and Matovani G: Medroxyprogesterone acetate in the management of cancer cachexia. J Expert Opin Pharmacother 10: 1359-1366, 2009.

18. Diament MJ, Peluffo GD, Stillitani I, Cerchiette LC, Navigante A, Ranuncolo SM and Klein SM: Inhibition of tumor progression and paraneoplastic syndrome development in a murine lung adenocarcinoma by medroxyprogesterone acetate and indomethacin. Cancer Invest 24: 126-131, 2006.

19. Yamashita JI and Ogawa M: Medroxyprogesterone acetate and cancer cachexia: interleukin-6 involvement. Breast Cancer 7: 130-135, 2000.

20. Kurebayashi J, Yamamoto S, Otsuki T and Sonoo H: Medroxyprogesterone acetate inhibits interleukin 6 secretion from KPL-4 human breast cancer cells both in vitro and in vivo: a possible mechanism of the anti-cachectic effect. Br J Cancer 79: 631-636, 1999.

21. McCarthy HD, Crowder RE, Dryden S and Williams G: Megestrol acetate stimulates food and water intake in the rat: effects on regional hypothalamic neuropeptide Y concentrations. Eur J Pharmacol 265: 99-102, 1994.

22. Zhou W, Jiang ZW, Jiang J and Li JS: The establishment of one kind of animal model of cancer cachexia. Chin J Exp Surg 21: 490-491, 2004.

23. Nai YJ, Jiang ZW, Wang ZM and Li JS: Effect of nuclear factor- $\kappa \mathrm{B}$ inhibitor on cancer cachexia. J Parenter Enteral Nutr 14: 270-274, 2007.

24. Tisdale MJ: Mechanisms of cancer cachexia. Physiol Rev 89: 381-410, 2009

25. Madeddu C and Mantovani G: An update on promising agents for the treatment of cancer cachexia. Curr Opin Support Palliat Care 3: 258-262, 2009.

26. Eley HL, McDonald PS, Russell ST and Tisdale MJ: Inhibition of activation of dsRNA-protein kinase and tumour growth inhibition. Cancer Chemother Pharmacol 63: 651-659, 2009.

27. Das SK, Eder S, Schauer S, Diwoky C, Temmel H, Guertl B, Gorkiewicz G, Tamilarasan KP, Kumari P, Trauner M, Zimmermann R, Vesely P, Haemmerle G, Zechner R and Hoefler G: Adipose triglyceride lipase contributes to cancerassociated cachexia. Science 333: 233-238, 2011.

28. Beck SA and Tisdale MJ: Effect of cancer cachexia on triacylglycerol/fatty acid substrate cycling in white adipose tissue. Lipids 39: 1187-1189, 2004.

29. Carson JA and Baltgalvis KA: Interleukin 6 as a key regulator of muscle mass during cachexia. Exerc Sport Sci Rev 38: 168-176, 2010.

30. Pajak B, Orzechowska S, Pijet B, Pijet M, Pogorzelska A, Gajkowska B and Orzechowski A: Crossroads of cytokine signaling - the chase to stop muscle cachexia. J Physiol Pharmacol 59 (Suppl 9): 251-264, 2008.

31. Busquets S, Serpe R, Sirisi S, Toledo M, Coutinho J, Martinez R, Orpi M, Lopes-Soriano FJ and Argiles JM: Megestrol acetate: Its impact on muscle protein supports its use in cancer cachexia. Clin Nutr 29: 733-737, 2010. 